\title{
Effect of nutrients on p70S6K activation in the bovine mammary gland*
}

\author{
C.A. Toerien ${ }^{1,3}$, D.R. Trout ${ }^{2}$ and J.P. Cant ${ }^{1}$ \\ ${ }^{I}$ Department of Animal and Poultry Science, \\ ${ }^{2}$ Department of Clinical Studies, \\ University of Guelph \\ Guelph, ON, N1G 2W1,Canada
}

\begin{abstract}
The effect of jugular infusions of glucose and amino acids on activation of p70S6K was studied in the bovine mammary gland. Cows were starved for $22 \mathrm{~h}$ to quench milk protein synthesis before resupplying EEA+Glc, Glc, Met+Lys, His, Leu or saline. Results implicate glucose as a regulator of global, rather than ribosomal, protein synthesis. EAA appear to play a far greater role in p70S6K regulation than glucose. His and Leu appear to act as metabolic agents in the mammary epithelial cell; Leu through elevating RNA levels thereby contributing to the long-term protein synthesis capacity, and His through stimulating protein translation.
\end{abstract}

KEY WORDS: translation initiation, amino acids, glucose, p70S6K

\section{INTRODUCTION}

In eukaryotic cells, nutrients play an important role in the cell signalling cascades involved in regulating translation. Amongst tissues, the high-producing bovine mammary gland is unrivalled in its ability to synthesize protein, yet little is known about the regulatory mechanisms involved in milk protein translation.

p70S6K (specifically S6K1) is a downstream target of phophoinositide-3 kinase (PI3K) and mammalian target of rapamycin (mTOR) signalling, and affects both translation initiation and the efficiency of translation. p70S6Kmediated phosphorylation of eIF4B, a cofactor of eIF4A, enhances the affinity of eIF4A for ATP and mRNA, thereby stimulating eIF4A helicase activity that facilitates ribosome loading (Raught et al., 2004). p70S6K further affects levels

\footnotetext{
* Supported by NSERC Canada and the Ontario Ministry of Agriculture and Food

${ }^{3}$ Corresponding author: e-mail: ctoerien@uoguelph.ca
} 
of translational machinery and translational efficiency by phosphorylating the $40 \mathrm{~S}$ ribosomal protein $\mathrm{S} 6$ which induces the selective translation of mRNAs coding for elongation factors, ribosomal proteins and poly(A)-binding protein (Meyuhas and Hornstein, 2000).

Activation of p70S6K occurs through a series of phosphorylation events on eight or more serine or threonine residues. Of the phosphorylation events, that of T389 closely corresponds to p70S6K activity in vivo (Pullen et al., 1998). p70S6K activation occurs in response to the energy and amino acid status of the cell. For example, in rat and mouse skeletal muscle, energy and protein intake enhanced both p70S6K phosphorylation (T389) and protein synthesis, and responses were independent of insulin (Svanberg et al., 1997). The goal of this study was to investigate the effect of glucose and essential amino acids on the phosphorylation of p70S6K in the bovine mammary gland.

\section{MATERIAL AND METHODS}

\section{Animals, infusion and sample collection}

In a $6 \times 6$ Latin Square design, 6 cows (initial: $69 \pm 4$ DIM; $43.4 \pm 0.5 \mathrm{~kg}$ milk/ d) were subjected every $14 \mathrm{~d}$ to a 31 -h fast. For the last $9 \mathrm{~h}$ of the fast, cows were infused introvenously with saline (Sal; negative control), essential amino acids plus glucose (EAA+Glc; positive control), Glc, Met+Lys, His, or Leu. Blood samples were collected at $-1 \mathrm{~d},-1 \mathrm{~min}$ and hourly during the infusion, and $+1 \mathrm{~d}$. Milk production response to infusion was calculated from milk produced in the front quarters between +1 and $+7 \mathrm{~h}$ of the 9 -h infusion. At $+9 \mathrm{~h}$, approximately $1.5 \mathrm{~g}$ of mammary tissue was harvested from a hind quarter. In successive periods, hind quarters were alternated so that each hind quarter was allowed $28 \mathrm{~d}$ to recover. Postbiopsy, cows were refed and infused with AA+Glc for $5 \mathrm{~h}$.

\section{Sample analyses}

Total RNA content ( $\mu \mathrm{g} / \mathrm{mg}$ tissue) of biopsy samples was determined using Tripure Isolation Reagent (Roche Diagnostics, Indianapolis, IN). p70S6K phosphorylation was assessed by immunoblot analysis following SDS-PAGE, using an anti-phospho-p70S6K (Thr389) antibody (Santa Cruz Biotechnology, Inc.). The amount of mammary protein secreted in response to treatment infusions $(\mathrm{g} / 6 \mathrm{~h})$ was calculated from the total milk produced in the front quarters combined, and the $\%$ protein content of the milk as determined by IR spectroscopy.

\section{Data and statistical analyses}

Results of RNA, phospho-p70S6K and milk protein produced were expressed as percentages where the response to the negative control, Sal, was set to $100 \%$. 
Data were analysed statistically as a 6x6 Latin Square design and results are presented as least squares means $\pm \mathrm{SE}$.

\section{RESULTS}

Compared to that of the Sal treatment, phosphorylation of p70S6K was higher in the EAA+Glc and Leu treatments $(\mathrm{P}<0.05$; Figure 1$)$ and tended to be higher in the His treatment $(\mathrm{P}=0.09)$. Infusion of EAA+Glc and Glc resulted in greater amounts of protein synthesized in the mammary gland than that of the Sal treatment $(\mathrm{P}<0.05$; Figure 1). Infusion of Met+Lys and His resulted in protein synthesis that did not differ from either Sal $(\mathrm{P}<0.05)$ or EAA+Glc $(0.1 \geq \mathrm{P} \geq 0.05)$. Only infusion of Leu resulted in elevated RNA content above that of Sal.

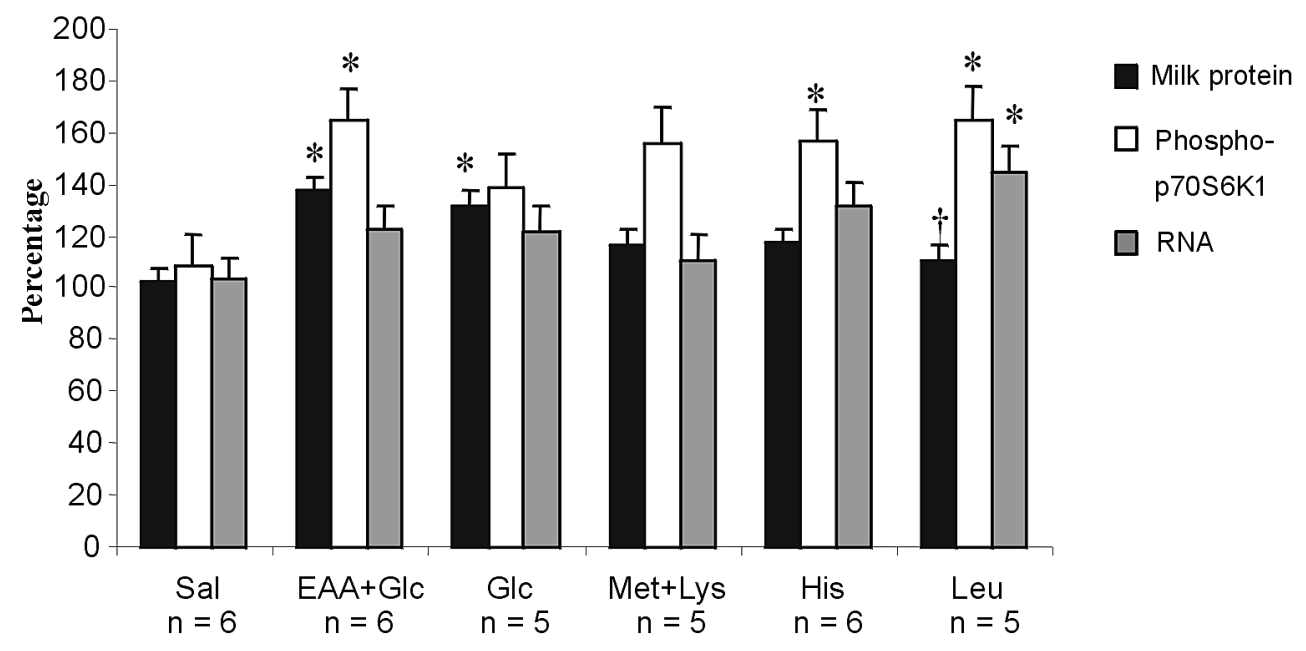

Treatments

Figure 1. Milk protein secretion by, and relative expression of phospho-p70S6K1 and RNA in, the bovine mammary gland in response to nutrient infusions. ${ }^{*},{ }^{\dagger}$ Within a parameter, treatments differ $(\mathrm{P}<0.1)$ from Sal $(*)$ or EAA + Glc $\left({ }^{\dagger}\right)$

\section{DISCUSSION}

Activation of p70S6K may occur in response to the energy status in the cell as well as to amino acid concentrations. In HCE-T cells, p70S6K is dephosphorylated in response to AMP-activated protein kinase (Tokunaga et al., 2003). Leu is proposed to cause activation of p70S6K in part by serving both as a mitochondrial fuel through oxidative carboxylation and an allosteric activator of glutamate dehydrogenase (Tokunaga et al., 2003). However, contrary to results from EAA+Glc, His or Leu infusion, Glc infusion neither activated p70S6K nor 
increased RNA above that of Sal. This lack of response suggests that EAA play a far greater role than glucose in p70S6K activation in the bovine mammary gland.

Whereas His and Leu both stimulated p70S6K phosphorylation, only Leu infusion resulted in elevated RNA levels and only His stimulated protein secretion. In ruminants, both His and Leu appear important to the mammary gland beyond their role as substrates. In goats, blood flow across the mammary gland and His extraction from the blood were upregulated in response to Hislacking AA infusates (Bequette et al., 2000). As a rule, Leu is taken up by the bovine mammary gland in quantities well in excess of what is secreted in milk protein. Because $70 \%$ of the RNA in a cell is ribosomal, the increase in mammary RNA suggests that Leu can influence levels of translational machinery, while His exerted a stronger effect on translation rate.

\section{CONCLUSIONS}

Glucose appears a powerful activator of milk protein synthesis but not $\mathrm{p} 70 \mathrm{~S} 6 \mathrm{~K}$. The EAA+Glc infusion increased milk protein produced and $\mathrm{p} 70 \mathrm{~S} 6 \mathrm{~K}$ phosphorylation, suggesting that EAAs play a far greater role in p70S6K regulation than glucose. Above the relative need for substrate, mammary uptake of Leu may ensure adequate levels of translational machinery, while that of His seems to involve a role in stimulating milk protein mRNA translation.

\section{REFERENCES}

Bequette B.J., Hanigan M.D., Calder A.G., Reynolds C.K., Lobley G.E., MacRae J.C., 2000. Amino acid exchange by the mammary gland of lactating goats when histidine limits milk production. J. Dairy Sci. 83, 765-775

Meyuhas O., Hornstein E., 2000. Translational control of TOP mRNAs. In: N. Sonenberg, J.W.B. Hershey, M.B. Matthews (Editors). Translational Control of Gene Expression. Cold Springs Harbor Laboratory Press, Plainview, NY, pp.671-694

Pullen N., Dennis P.B., Andjelkovic M., Dufner A., Kozma S.C., Hemmings B.A., Thomas G., 1998. Phosphorylation and activation of p70S6K by PDK1. Science 279, 707-710

Svanberg E., Jefferson L.S., Lundholm K., Kimball S.R., 1997. Postprandial stimulation of muscle protein synthesis is independent of changes in insulin. Amer. J. Physiol. - Endocrinol. Met. 271, E841-E847

Tokunaga C., Yoshino K., Yonezawa K., 2003. mTOR integrates amino acid- and energy-sensing pathways. Biochem. Biophys. Res. Commun. 313, 443-446 